\title{
Desinformação sobre o Covid-19 no WhatsApp: a pandemia enqua- drada como debate político
}

\author{
Disinformation about Covid-19 on WhatsApp: the pandemic framed as political debate
}

\author{
Felipe Bonow Soares \\ Doutor em Comunicação e Informação \\ Universidade Federal do Rio Grande do Sul \\ fbonowsoares@gmail.com \\ Raquel Recuero \\ Doutora em Comunicação e Informação \\ Universidade Federal do Rio Grande do Sul \\ raquel.recuero@ufpel.edu.br \\ Taiane Volcan \\ Doutora em Letras \\ Universidade Federal de Pelotas \\ taianevolcan@gmail.com \\ Giane Fagundes \\ Mestranda em em Letras \\ Universidade Federal de Pelotas \\ gianehfagundes@gmail.com \\ Giéle Sodré \\ Graduando em Jornalismo \\ Universidade Federal de Pelotas \\ gielesodre@gmail.com
}

\section{Resumo}

Neste artigo, discutimos como é enquadrada a desinformação sobre o Covid-19 no WhatsApp no Brasil. Nossos objetivos são: (1) analisar a influência do discurso político nestes processos e (2) identificar as características da desinformação sobre o Covid-19 nesta ferramenta. Para isso, utilizamos a análise de conteúdo em um conjunto de 802 mensagens coletadas por meio do Monitor do WhatsApp em março e abril de 2020. Os nossos principais resultados mostram que: (1) a pandemia foi enquadrada como debate político e a desinformação foi utilizada para fortalecer uma narrativa próBolsonaro em momento de crise do governo; e (2) há grande prevalência de teorias da conspiração nas mensagens analisadas e a opinião aparece como a principal estratégia discursiva, resultado que pode estar relacionado com as características da plataforma.

\section{Palavras-Chave}

Análise de conteúdo. Covid-19. Desinformação. Discurso politico. WhatsApp.

\section{Abstract}

In this paper, we discuss how the disinformation about Covid-19 is framed on WhatsApp in Brazil. Our aims are: (1) analyze political discourse influence in these processes and (2) identify the disinformation about Covid-19 characteristics on WhatsApp. We used content analysis to analyze 802 messages collected using the WhatsApp Monitor during March and April, 2020. Our main findings are: (1) the pandemic was framed as political debate and the disinformation was used to strengthen a proBolsonaro narrative at a time of government crisis; and (2) conspiracy theories are highly prevalent in 
the messages we analyzed, and opinion is the main discursive strategies, which might be related to the characteristics of the platform.

\section{Keywords}

Content analysis. Covid-19. Disinformation. Political Discourse. WhatsApp.

\section{INTRODUÇÃO}

O crescimento da pandemia do Covid-19 foi acompanhado também por um fenômeno de espalhamento de desinformação, chamado de "infodemia" pela Organização Mundial da Saúde $(\mathrm{OMS})^{1}$. O Brasil foi fortemente afetado pelos dois fenômenos, estando entre os países com maiores números de casos e mortes pela doença e também sendo afetado pelo espalhamento de informações falsas (ARAÚJO \& OLIVEIRA, 2020; RECUERO \& SOARES, 2020; RECUERO, SOARES \& ZAGO, 2021; RICARD \& MEDEIROS, 2020). O espalhamento de desinformação favorece a polarização de sentimentos relacionados a pandemia (ALLCOTT et al., 2020), o que dificulta uma ação coletiva coordenada, necessária para o combate ao vírus.

A desinformação sobre o Covid-19 no Brasil tem sido impulsionada pelo discurso político e pela falta de alinhamento entre as autoridades (RECUERO \& SOARES, 2020). O presidente brasileiro Jair Bolsonaro, por exemplo, minimizou a pandemia diversas vezes desde seu início². Bolsonaro disse que a pandemia não passava de uma "gripezinha", falou que as ações de combate ao vírus representavam uma "histeria" e que a preocupação com o espaIhamento da doença era uma "fantasia" propagada pela mídia. Além disso, frequentemente participou de aglomerações com apoiadores, inclusive abraçando outras pessoas sem o uso de máscaras faciais ${ }^{3}$. Ao mesmo tempo, o então ministro da saúde Henrique Mandetta endossou as medidas de combate ao Covid-19 sugeridas pela OMS e adotadas por diversos governadores e prefeitos. O posicionamento de Mandetta, governadores e prefeitos, assim como as medidas que adotaram, resultaram no aumento de sua popularidade, enquanto a de Bolsonaro estava em queda ${ }^{4}$. Estas ações geraram atritos entre Bolsonaro e governadores e prefeitos ${ }^{5}$, assim como entre Bolsonaro e Mandetta, que acabou demitido em abril ${ }^{6}$.

Neste artigo, exploramos a desinformação sobre o Covid-19 espalhada no WhatsApp. Escolhemos o WhatsApp porque é um espaço relevante de circulação de informações políticas no Brasil, já que é o aplicativo de mensagens mais popular no país (RESENDE et al., 2018). O aplicativo é considerado por $57 \%$ de brasileiros como uma fonte importante ou muito importante no acesso a informações políticas (BAPTISTA et al., 2019). Além disso, é também identificado como o principal meio de espalhamento de desinformação no país (NEWMAN et al., 2020) e teve papel central no espalhamento de informações falsas sobre diversos acontecimentos políticos no Brasil (REIS et al., 2020). O problema de pesquisa que guia este estudo é: quais os enquadramentos e estratégias discursivas da desinformação sobre Covid-19 no WhatsApp no contexto brasileiro? Os nossos objetivos são: (1) analisar

\footnotetext{
${ }^{1}$ https://www.who.int/teams/risk-communication/infodemic-management/.

${ }^{2}$ https://congressoemfoco.uol.com.br/governo/gripezinha-e-histeria-cinco-vezes-em-que-bolsonarominimizou-o-coronavirus/.

${ }^{3}$ https://noticias.uol.com.br/politica/ultimas-noticias/2020/05/17/bolsonaro-esteve-em-media-em-umaaglomeracao-por-dia-durante-a-pandemia.htm.

${ }^{4}$ https://www1.folha.uol.com.br/poder/2020/03/avaliacao-de-bolsonaro-na-gestao-da-crise-e-muito-pior-quea-de-governadores-e-ministerio-diz-datafolha.shtml.

${ }^{5}$ https://www.dw.com/pt-br/pandemia-deflagra-crise-entre-presidente-e-governadores/a-52927722.

${ }^{6}$ https://www1.folha.uol.com.br/poder/2020/04/relembre-os-embates-entre-bolsonaro-e-mandetta-na-crisedo-coronavirus.shtml.
} 
como o discurso político é utilizado para enquadrar a desinformação sobre o Covid-19 e (2) identificar as características da desinformação sobre o Covid-19 no WhatsApp. Para isso, utilizamos o Monitor do WhatsApp (RESENDE et al., 2018) para coletar as mensagens mais compartilhadas em mais de 500 grupos públicos na plataforma em março e abril de 2020 . 0 conjunto de dados que analisamos neste estudo é composto por 802 mensagens que contêm desinformação sobre o Covid-19.

Iniciamos o artigo com as discussões teóricas sobre o conceito de desinformação e seus tipos; e as estratégias discursivas utilizadas no discurso político e na produção de desinformação. Na sequência, detalhamos os procedimentos metodológicos adotados neste estudo. Na seção de resultados, discutimos os principais achados da nossa análise e como estão relacionados aos nossos objetivos de pesquisa.

\section{DESINFORMAÇÃO NO WHATSAPP}

Neste artigo, entendemos desinformação como um fenômeno que compreende a circulação de informações distorcidas, manipuladas ou inteiramente falsas que são produzidas com a função de enganar (FALLIS, 2015; BENKLER, FARIS \& ROBERTS, 2018). A desinformação, portanto, é intencionalmente criada para manipular a opinião pública, gerando efeitos negativos nas discussões da esfera pública (TUCKER et al., 2018). Ela é frequentemente associada às mídias sociais porque se favorece de suas dinâmicas de compartilhamento de conteúdo em seu espalhamento em larga escala (WARDLE \& \& DERAKHSHAN, 2017).

A discussão da desinformação a partir da intencionalidade possui alguns problemas, por exemplo, porque (1) não é possível avaliar a intencionalidade dos indivíduos na disseminação de desinformação e (2) os contextos de espalhamento de desinformação frequentemente estão associados a disputas de sentido, mais do que a simples intenção de enganar (OLIVEIRA, 2020a). Ainda assim, em alguns contextos políticos é possível observar níveis de organização na produção e disseminação de desinformação, o que indica que a desinformação é criada com o objetivo de afetar discussões públicas (GUESS \& LYONS, 2020). Este contexto parece estar presente no caso analisado, já que a desinformação sobre Covid-19 tem sido mobilizada por atores políticos como forma de fortalecer um discurso que os favoreça (GRUZD \& MAI, 2020; RECUERO \& SOARES, 2020; RICARD \& MEDEIROS, 2020). Assim, não buscamos compreender a intencionalidade de cada indivíduo que compartilha mensagens desinformativas, mas caracterizar um contexto mais amplo onde há alguma forma de organização para a produção e disseminação de desinformação, que favorece determinados atores políticos.

Outra problemática associada ao conceito de desinformação é que nos usos do conceito frequentemente há uma busca por produzir uma dualidade entre detentores da verdade (como o jornalismo) e atores que buscam gerar desestabilidade, porém esta dualidade é limitada já que o contexto da circulação da desinformação é bem mais complexo (OLIVEIRA, 2020a). Além disso, atores como a própria imprensa podem colaborar para o espalhamento da desinformação (TSFATI et al. 2020). Neste sentido, reconhecemos as limitações do conceito, mas utilizamos desinformação para designar o conteúdo que analisamos como forma de delimitação analítica do fenômeno que estamos observando. Além disso, a discussão a partir da desinformação nos permite observar seus diferentes tipos a partir de estudos anteriores, como discutiremos ao final desta seção. De forma específica, poderemos discutir como estes tipos são observados no WhatsApp, já que outros estudos observaram outras pla- 
taformas (BRENNEN et al., 2020; RECUERO \& SOARES, 2020; RECUERO, SOARES \& ZAGO, 2021 são alguns exemplos).

Particularmente, o WhatsApp é visto como uma fonte central no espalhamento de desinformação no Brasil (NEWMAN et al., 2020). Estudos apontam que o aplicativo de mensagens teve papel central no espalhamento de desinformação nas eleições brasileiras de 2018 e também em outros momentos políticos importantes (REIS et al., 2020). No Brasil, o WhatsApp lidera o ranking de aplicativo mais baixado, assim como de usuários ativos ${ }^{7}$. 0 relatório de consumo de notícias digitais da Reuters Institute indica que $83 \%$ dos brasileiros utilizam o WhatsApp (mais do que qualquer outra plataforma), sendo que $48 \%$ utilizam o aplicativo para consumo de notícias. De forma semelhante, os resultados de Baptista et al. (2019) mostram que $57 \%$ dos brasileiros consideram a plataforma como uma fonte importante de informações políticas. Com base nestes dados, entendemos que o que circula no WhatsApp tem grande impacto e, portanto, é importante compreender o espalhamento de desinformação na plataforma.

Além disso, o WhatsApp tem particulares que afetam a forma como a desinformação é produzida e disseminada no aplicativo. As práticas de usos das plataformas estão relacionadas com suas funcionalidades técnicas, que afetam a forma como os usuários se relacionam com as tecnologias (D'ANDRÉA, 2020). Assim, os usos do WhatsApp são influenciados pelas suas affordances. Por affordances nos referimos ao processo interativo entre a tecnologia e suas ferramentas e os usuários e as formas como se apropriam das ferramentas (EVANS et al., 2017). Isto é, as tecnologias indicam os seus usos em função das ferramentas técnicas que disponibilizam, mas os usos são também dependentes da forma como os usuários interagem com estas plataformas. No caso particular do WhatsApp, que é um aplicativo de mensagens pessoais, as suas affordances fazem com que os usuários percebam a plataforma como um espaço mais privado, de forma que isso afeta suas ações e a forma como interagem com outros usuários (VALERIANI \& VACCARI, 2017). Desta forma, as características da desinformação que circula no WhatsApp são diferentes da desinformação que circula em outras plataformas, especialmente as que possuem um caráter mais público (RECUERO, SOARES \& VINHAS, 2021).

É importante, portanto, entender os diferentes tipos de desinformação. Wardle (2019) divide a desinformação em sete tipos: sátiras e paródias, conexões falsas, conteúdo enganoso, contexto falso, conteúdo impostor, conteúdo manipulado e conteúdo fabricado. Brennen et al. (2020) se apropriam das categorias de Wardle e dividem elas em três tipos: sátiras e paródias, conteúdo reconfigurado (conteúdo enganoso, contexto falso e conteúdo manipulado) e conteúdo fabricado (conteúdo impostor e informação fabricada). Neste estudo, dividimos a desinformação em três tipos:

(1) Distorção: conteúdo baseado em informações parcialmente verdadeiras, que são distorcidas para gerar conclusões equivocadas. Inclui conexões falsas, informações fora de contexto, enquadramentos enganosos e informações reconfiguradas de alguma forma para enganar.

(2) Informação fabricada: informações completamente falsas, criadas para enganar. Incluem, por exemplo, áudios falsos, dados criados sem base em evidências, entre outras estratégias.

\footnotetext{
${ }^{7}$ https://valorinveste.globo.com/mercados/brasil-e-politica/noticia/2020/01/20/whatsapp-foi-o-aplicativo-
} mais-baixado-no-brasil-e-no-mundo-em-2019.ghtml. 
(3) Teorias da conspiração: narrativas não comprovadas que falam sobre alguma forma de conspiração ou plano obscuramente orquestrado por indivíduos ou grupos (SUNSTEIN \& VERMEULE, 2009). Ainda que as teorias da conspiração não sejam classificadas como um dos tipos de desinformação por Wardle (2019) entendemos este tipo de conteúdo como desinformação, porque geram interpretações equivocadas a partir de informações falsas ou distorcidas. Além disso, outros estudos já identificaram que teorias da conspiração também aparecem associadas ao espalhamento de informações falsas sobre o Covid-19 (BRENNEN et al., 2020; GRUZD \& MAl, 2020; PAPAKYRIAKOPOULOS, SERRANO \& HEGELICH, 2020; RECUERO \& SOARES, 2020). Entendemos, portanto, que assim como outros tipos de desinformação, as teorias da conspiração auxiliam na formação de "narrativas alternativas" para explicar um determinado acontecimento ou uma série de eventos (STARBIRD, 2017).

É importante ressaltar que enquanto as duas primeiras categorias são necessariamente distintas, as teorias da conspiração podem ser baseadas em elementos inteiramente falsos ou podem ser criadas a partir de distorções. As teorias da conspiração costumam seguir alguma forma de racionalização para contestar explicações oficiais de acontecimentos sociais (HARAMBAM \& AUPERS, 2015), utilizando inclusive conteúdo produzido pela imprensa e se apropriando de diferentes fontes de informação (OLIVEIRA, 2020b). As teorias da conspiração são produzidas principalmente em um contexto de crises de confiança com instituições modernas, como o jornalismo, a ciência e instituições governamentais (ALBUQUERQUE \& QUINAN, 2019). Assim, as teorias da conspiração podem se apropriar de elementos tanto da distorção quanto da informação fabricada. Como detalhamos na seção metodológica deste artigo, a criação das categorias se deu a partir de uma pré-análise dos dados. Decidimos incluir as teorias da conspiração como uma categoria específica porque foi um tipo de discurso que apareceu de forma prevalente nos dados. Assim, entendemos que seria relevante diferenciar a teoria da conspiração, como uma construção discursiva com características específicas, dos outros dois tipos de desinformação.

\section{ESTRATÉGIAS DISCURSIVAS}

O espalhamento de desinformação também depende de estratégias discursivas, que servem para legitimação e aumento da visibilidade das mensagens que propagam desinformação (SOARES, 2019; RECUERO, 2020; RECUERO, SOARES \& VINHAS, 2021).

Para a Análise Crítica do Discurso, as estratégias textuais estão relacionadas às práticas discursivas que, por sua vez, estão relacionadas às práticas socioculturais (FAIRCLOUGH, 2001). Deste modo, as estratégias discursivas são utilizadas para construir um determinado enquadramento de um discurso, cujas estruturas de texto são constituídas para legitimar o mesmo. O conceito de estratégia discursiva foi proposto por Wodak (2001) como um conjunto "mais ou menos acurado e mais ou menos intencional de práticas, incluindo práticas discursivas, para atingir um objetivo particular social, político, psicológico ou linguístico" 8 (online). Para a autora, uma estratégia discursiva é também uma prática de negociação de poder. Para Wodak, são cinco as estratégias discursivas possíveis: (1) Nominação, referente à construção discursiva de eventos, sujeitos e etc.; (2) Predicação, referente à qualificação desses eventos, sujeitos e etc.; (3) Argumentação, referente ao questionamento e justificati-

${ }^{8}$ Tradução dos autores: "a more or less accurate and more or less intentional plan of practices including discursive practices adopted to achieve a particular social, political, psychological and linguistic aim". 
va dos argumentos de correção e verdade; (4) Perspectivização ou enquadramento, referese à expressão de envolvimento ou distanciamento do emissor; (5) Intensificação ou Mitigação, refere-se ao uso de elementos que modifiquem a força ilocutória. A estratégia discursiva, assim, é um modo intencional de enquadramento do discurso, de modo a criar práticas relacionadas específicas.

Van Leeuwen (2007) trabalha com estratégias específicas de legitimação para as práticas discursivas. É importante compreender que estratégias discursivas também são utilizadas para a legitimação de certas práticas sociais e enquadramentos discursivos que visam influenciar essas práticas. Para o autor, há modos de legitimação relacionados à (1) autorização (relacionado ao argumento da autoridade); (2) racionalização (quando um argumento racional é apresentado como legitimador); (3) avaliação moral (legitimação relacionada a um discurso de valor, certo e errado); e (4) mythopoesis (legitimação relacionada a um discurso de narrativas de ação e punição).

Para este trabalho, definimos a análise de três estratégias discursivas de legitimação para o conteúdo desinformativo no WhatsApp. Essas estratégias foram construídas a partir de um trabalho de pré-análise dos dados, que utilizou o framework da Análise Crítica do Discurso (FAIRCLOUGH, 2001) para constituir essas categorias.

São elas:

(1) Uso de opinião: esta é uma estratégia relacionada a forma como a desinformação é apresentada. Neste estudo, considerados tanto a apresentação de uma opinião pessoal, quanto reprodução de opiniões de terceiros. Como o WhatsApp é visto como uma plataforma mais privada e de interações com contatos mais próximos (VALERIANI \& VACCARI, 2017), a opinião pode reforçar um aspecto de informalidade em interações menos públicas e facilitar o espalhamento da desinformação. $\mathrm{O}$ uso da opinião é também uma estratégia argumentativa de validação de um discurso, pois o locutor expressa sua concordância com ele (WODAK, 2001). A opinião também pode nominar e predicar o evento desinformativo (WODAK, 2001). A opinião pode utilizar vários modos de legitimação, embora geralmente foque na avaliação moral (bons valores associados a uma data desinformação) ou racionalização (mais raro, argumentação de que a desinformação é racional).

(2) Uso de autoridades: a autoridade é uma estratégia que se apropria da reputação de um indivíduo ou organização. Assim, o uso de autoridade aparece como uma forma de legitimação do discurso em função do indivíduo ou instituição utilizado para dar credibilidade ao discurso (VAN LEEWEN, 2007). O argumento da autoridade é uma estratégia de perspectivização (WODAK, 2001), utilizada no sentido de construir legitimação a partir da proximidade do locutor com a questão. É também uma estratégia de intensificação (WODAK, 2001), a partir do momento em que potencializa e fortalece a mensagem.

(3) Call to action: esta estratégia serve para motivar usuários a realizar alguma ação. No caso específico do WhatsApp, o call to action é frequentemente utilizado para mobilizar usuários a compartilhar mensagens, já que o conteúdo depende da ação dos usuários para circular (RECUERO, SOARES \& VINHAS, 2021). O call to action foi escolhido por ser, ao mesmo tempo, uma estratégia de intensificação da mensagem (WODAK, 2001), na medida em que agrega a seu senso de urgência, e de perspectivização (WODAK, 2001), na medida em que inclui o receptor exigindo-lhe uma ação específica. O call to action legitima uma desinformação a partir 
do momento que the confere avaliação moral (o compartilhamento da informação é valorado como "bom").

Olhar para os tipos de desinformação, assim como as estratégias discursivas é relevante para compreender as características da desinformação no WhatsApp. Em específico, entendemos que as affordances da plataforma, assim como a percepção dos usuários sobre o tipo de interação que realizam no aplicativo, geram um contexto distinto de outras plataformas com características mais "públicas", como Facebook e Twitter. Portanto, queremos explorar como as especificidades do WhatsApp afetam na forma como a desinformação ocorre na plataforma.

\section{METODOLOGIA}

Com o objetivo de analisar (1) a influência do discurso político no enquadramento da desinformação sobre o Covid-19 no WhatsApp e (2) as características das mensagens que espalham desinformação na plataforma, o primeiro passo foi buscar um conjunto de dados adequado para explorar estas questões. Para isso, utilizados o Monitor do WhatsApp (RESENDE et al., 2018), que é um sistema que rastreia dados de mais de 500 grupos políticos públicos no Brasil. O Monitor do WhatsApp não armazena dados sensíveis de usuários, apenas o conteúdo das mensagens compartilhadas. Como o Monitor do WhatsApp armazena separadamente texto, imagens, vídeos e áudios, optamos por focar nos textos das mensagens.

Para montar o nosso conjunto de dados, inicialmente acessamos a plataforma e coletamos todas as mensagens que consideramos conter desinformação sobre o Covid-19 e que foram compartilhadas pelo menos 20 vezes em um dia nos meses de março e abril de 2020 . Nós optamos por analisar este período de tempo porque foi quando o Covid-19 se espalhou pelo Brasil, assim como foram tomadas as primeiras medidas de combate ao vírus no país. $\mathrm{O}$ nosso conjunto de dados inicial era composto por 810 mensagens. Durante a análise dos dados por meio da análise de conteúdo (discutida abaixo), oito mensagens foram excluídas do conjunto de dados, já que no processo de classificação e validação dos dados foi considerado que estas não reproduziam desinformação. Isto é, estas mensagens falavam sobre Covid-19, mas na análise de conteúdo identificamos que não reproduziam informações distorcidas ou fabricadas e nem teorias da conspiração. Assim, o nosso conjunto de dados final tem 802 mensagens. No total, estas mensagens alcançaram quase 35 mil compartilhamentos somente nos grupos monitorados pelo Monitor do WhatsApp, o que dá uma dimensão do impacto social que tiveram no contexto da pandemia.

Inicialmente, fizemos uma pré-análise qualitativa dos dados, buscando compreender elementos que pudessem ser delimitados como estratégicos para o espalhamento das mensagens. Dentro deste estudo inicial, observamos todas as mensagens e discutimos, entre os autores, as estratégias que estavam sendo utilizadas para validar e estimular a circulação dos discursos. Essas categorias foram construídas a partir do framework de estratégias discursivas de Wodak (2001) e de modos de legitimação de Van Leeuwen (2007). A partir desta discussão, chegamos às três categorias que apresentamos anteriormente para a análise. 0 mesmo ocorreu com a definição das categorias utilizadas para os tipos de desinformação.

Para os próximos passos de análise dos dados, optamos pela análise de conteúdo (KRIPPENDORFF, 2013), para um foco mais quantitativo. Para melhor compreender as características da desinformação sobre o Covid-19 no WhatsApp, dois analistas independentes 
classificaram todas por (1) tipo de desinformação e (2) estratégias discursivas. Ainda que as mensagens pudessem incluir mais de um tipo de desinformação (por exemplo, teorias da conspiração podem ser baseadas em informações distorcidas), para o tipo de desinformação consideramos as categorias mutuamente exclusivas, de forma que identificamos o tipo predominante na mensagem. Já para as estratégias discursivas, a análise foi simplesmente se uma estratégia era utilizada ou não (independentemente das outras), de forma que mensagens poderiam utilizar as três estratégias ou mesmo não utilizar nenhuma das estratégias.

$\mathrm{Na}$ classificação dos tipos de desinformação, a concordância entre os analistas foi moderada a forte, tendo um coeficiente Krippendorff's Alpha ${ }^{9}$ de 0,601. Para as estratégias discursivas, a concordância entre os analistas foi forte, alcançando os coeficientes Krippendorff's Aplha 0,612 para "opinião", 0,651 para "autoridade" e 0,65 para "call to action". Utilizamos um terceiro analista para desempatar as discordâncias entre os dois analistas iniciais, assim pelo menos dois analistas concordaram na classificação final que adotamos neste artigo. Portanto, ainda que estas categorias sejam interpretativas em algum nível, alcançamos bons índices de concordância entre os analistas e garantimos a confiabilidade da análise com o uso de um terceiro analista para desempates. Estas análises também serviram para validar a presença da desinformação nas mensagens inicialmente coletadas para a análise, de forma que oito foram retiradas do nosso conjunto de dados porque durante a análise de conteúdo os analistas consideraram que não reproduziam nenhum tipo de desinformação.

Como também adotamos como objetivo analisar a influência do discurso político na desinformação sobre o Covid-19 no WhatsApp, identificamos os tópicos presentes nas mensagens. Após uma pré-análise exploratória, listamos quinze tópicos frequentes nas mensagens: Bolsonaro, China, congresso, cura, distanciamento social, economia, esquerda, governadores e prefeitos, Henrique Mandetta, hospitais, mídia, ministros (exceto Mandetta), Organização Mundial da Saúde, países do exterior (exceto China), Supremo Tribunal Federal. Os tópicos não eram exclusivos, de forma que mensagens podiam conter mais de um tema. Para identificar os tópicos nas mensagens, três analistas independentes classificaram o nosso conjunto de dados. A concordância foi alta, alcançando um coeficiente Krippendorff's Aplha de 0,675 . Para a decisão final, nós utilizamos a concordância de pelo menos dois analistas.

Para melhor explorar os nossos dados, nós realizamos testes estatísticos de correlação. Assim, foi possível observar quais tópicos aparecem mais frequentemente juntos, quais os tópicos são mais predominantes em determinados tipos de desinformação e, por fim, quais as relações entre os tipos de desinformação e as estratégias discursivas. Para a visualização das correlações entre os tópicos, nós criamos um grafo de rede em que cada tópico é um nó e as conexões entre eles representam uma correlação positiva significativa ${ }^{10}$. Utilizamos métricas de grupabilidade (BLONDEL et al, 2008) e de centralidade para identificar os temas mais centrais para as diferentes mensagens com desinformação sobre Covid-19 no WhatsApp.

Também com o objetivo de observar a influência do discurso político e dos acontecimentos públicos na desinformação sobre o Covid-19 no WhatsApp, acompanhamos os principais acontecimentos em portais de notícias. Esta estratégia foi utilizada para analisar o

\footnotetext{
${ }^{9}$ Utilizamos o ReCal2 e ReCal3 para realizar os testes de Krippendorf's Aplha (FREELON, 2010).

${ }^{10}$ Ainda que algumas das correlações significativas sejam correlações fracas (abaixo de 0,2), decidimos manter estas na análise porque o objetivo é mais observar padrões nos dados do que efeitos entre as categorias estudadas.
} 
impacto do discurso público no espalhamento de desinformação, assim como as formas como o discurso político refletiu no conteúdo das mensagens desinformativas.

\section{RESULTADOS}

Em um primeiro momento, nós analisamos a distribuição das mensagens desinformativas ao longo do tempo e comparamos com os principais acontecimentos políticos. Em função da sua atuação no relacionada ao Covid-19, Bolsonaro foi alvo de protestos em março. A partir do dia 17, brasileiros diariamente bateram panelas em suas janelas e sacadas e pediram pelo impeachment do presidente ${ }^{11}$. No mesmo período, governadores e prefeitos anunciaram medidas de distanciamento social como forma de controlar o espalhamento do vírus. O então ministro da saúde, Henrique Mandetta, apoiou as medidas dos governadores e prefeitos. Surgiu, portanto, um cenário de crise para Bolsonaro.

O político respondeu de maneira mais enfática a esta crise em pronunciamento na televisão aberta no dia 24 de março. No pronunciamento, Bolsonaro criticou as medidas adotadas por governadores, minimizou a ameaça do Covid-19, culpou a mídia por "histeria" e defendeu a "volta a normalidade" com reabertura de escolas e o fim do isolamento social ${ }^{12}$. Em novo pronunciamento, no dia 31 de março, Bolsonaro defendeu que era necessário garantir a estabilidade da economia e que as pessoas necessitavam voltar a trabalhar para evitar o aumento do desemprego e dificuldades econômicas individuais ${ }^{13}$.

Ao analisar a distribuição do compartilhamento de desinformação ao longo do tempo, identificamos o impacto dos dois pronunciamentos de Bolsonaro no espalhamento de desinformação sobre o Covid-19 no WhatsApp. Em particular, no dia seguinte ao primeiro pronunciamento identificamos o pico de compartilhamento de desinformação nos nossos dados. O dia seguinte ao segundo pronunciamento também teve um aumento no compartiIhamento de mensagens desinformativas (Figura 1).

Figura 1 - Distribuição do compartilhamento de mensagens ao longo do tempo

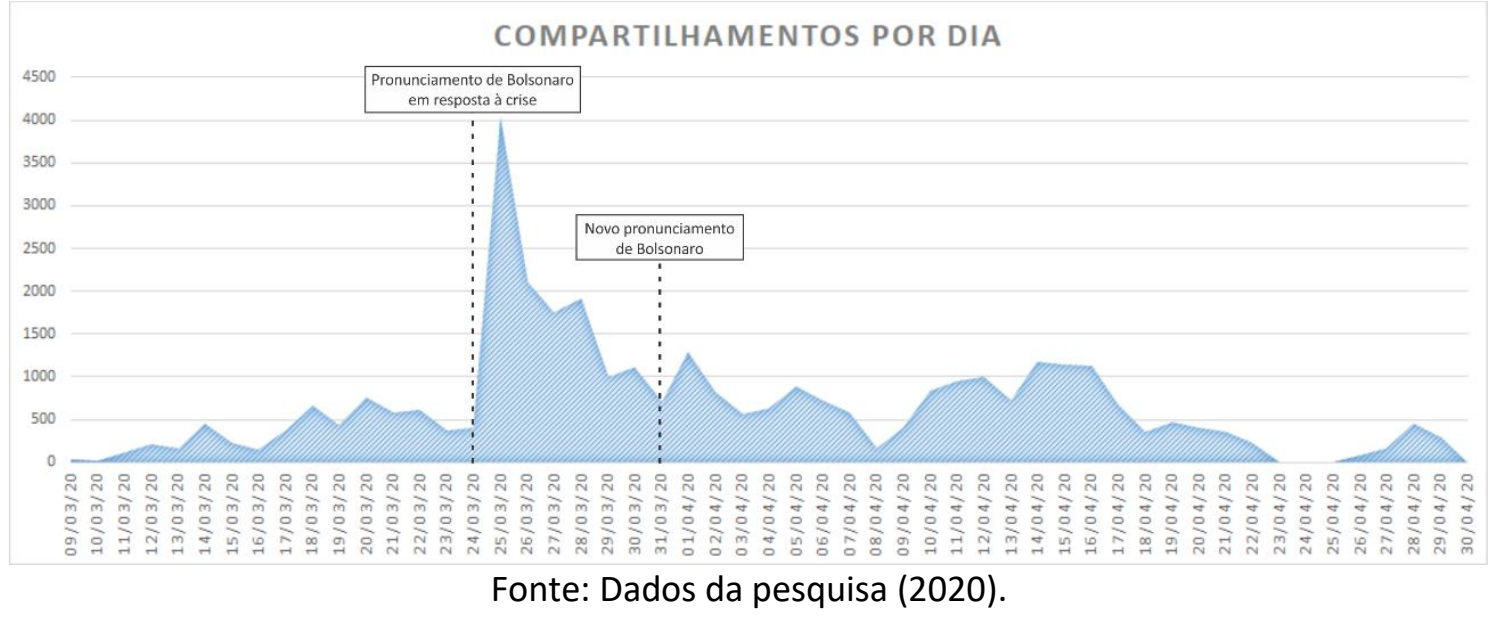

\footnotetext{
${ }^{11}$ https://www1.folha.uol.com.br/poder/2020/03/bolsonaro-e-alvo-de-panelaco-em-cidades-brasileiras-pelosegundo-dia-seguido.shtml.

${ }^{12}$ https://www.correiobraziliense.com.br/app/noticia/politica/2020/03/24/interna_politica,836430/bolsonaropede-reabertura-de-escolas-e-critica-governadores.shtml.

${ }^{13}$ https://www1.folha.uol.com.br/poder/2020/03/em-novo-pronunciamento-bolsonaro-distorce-oms-e-voltaa-igualar-empregos-e-vidas-diante-do-coronavirus.shtml.
} 
Em outro exemplo, notamos também a influência de declarações de Bolsonaro na produção de desinformação sobre Henrique Mandetta. O período de crise entre os dois, que envolveu atritos públicos, foi também o período com maior número de mensagens desinformativas sobre Mandetta. $\mathrm{O}$ atrito entre os dois teve início com as discordâncias sobre a forma de combater o vírus, ainda no meio de março, e se acirrou a partir do final de março quando os dois criticaram um ao outro publicamente. As mensagens desinformativas atacavam Mandetta, o associavam a esquerda e classificavam suas ações como forma de prejudicar Bolsonaro. $\mathrm{O}$ auge da crise entre os dois, a partir do final de março, também foi quando Mandetta alcançou maior popularidade entre os brasileiros. Com a demissão de Mandetta, também diminui o número de mensagens sobre ele (Figura 2).

Figura 2 - Distribuição de mensagens sobre Henrique Mandetta

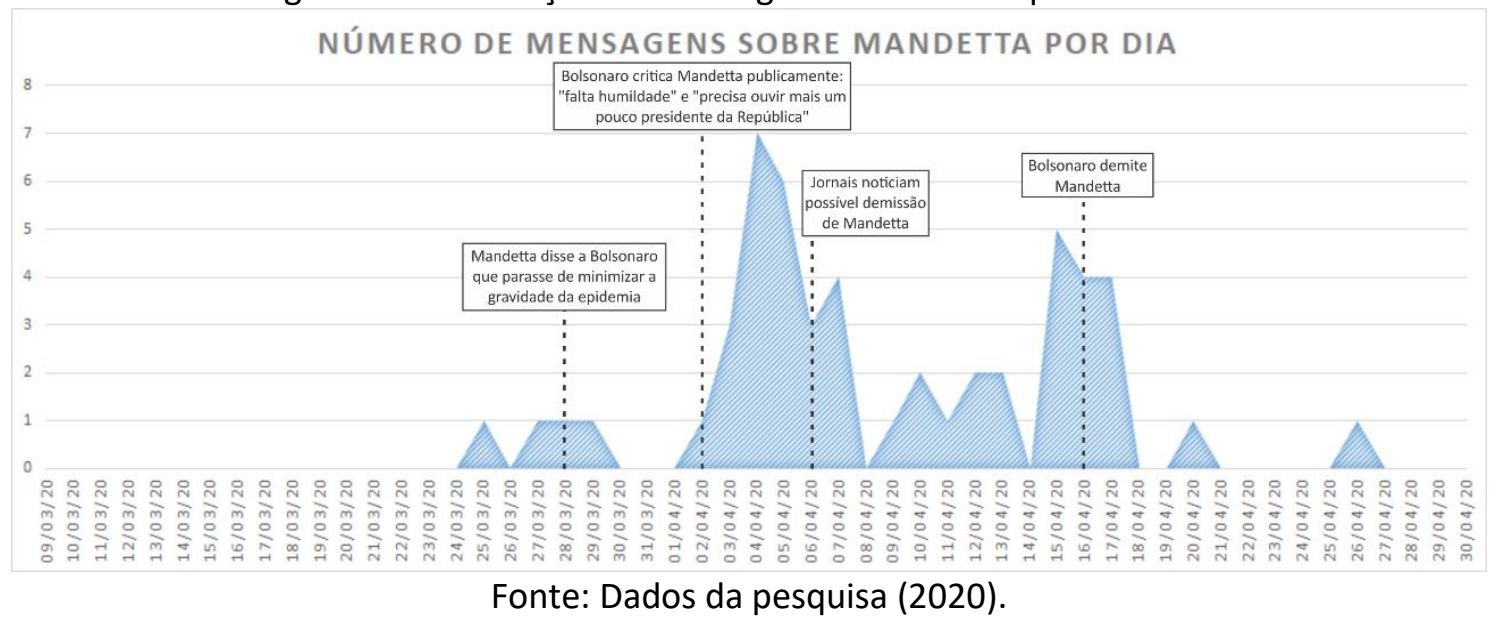

Para explorar mais a fundo o impacto do discurso político na desinformação sobre o Covid-19 no WhatsApp, analisamos os temas presentes nas mensagens. A nossa análise dos tópicos se dá de duas formas: com relação a frequência, de forma que podemos observar quais mais apareceram (Figura 3); e na observação das correlações, para identificar as conexões entre os tópicos (Figura 4).

Figura 3 - Frequência dos tópicos nas mensagens

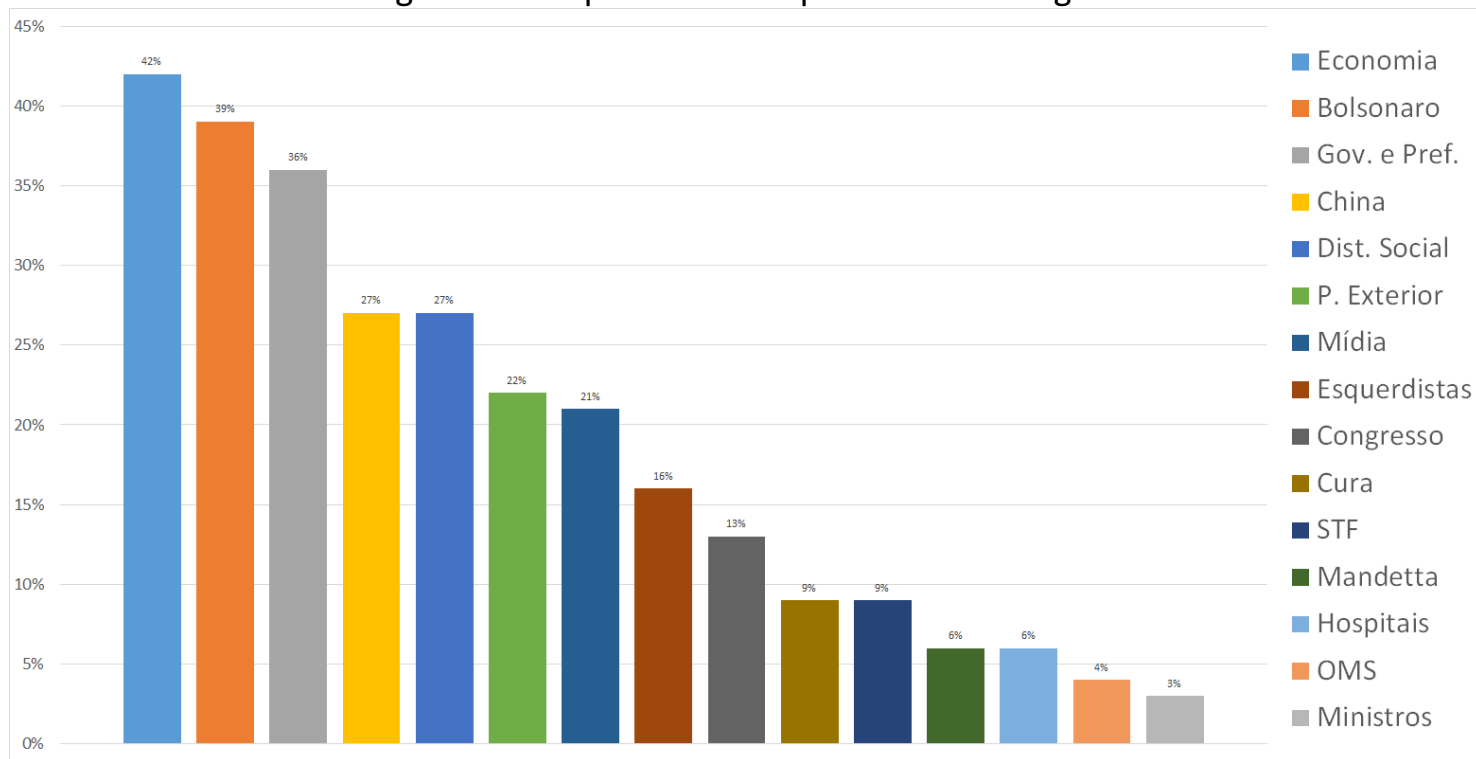

Fonte: Dados da pesquisa (2020). 
Figura 4 - Rede de correlações entre os temas

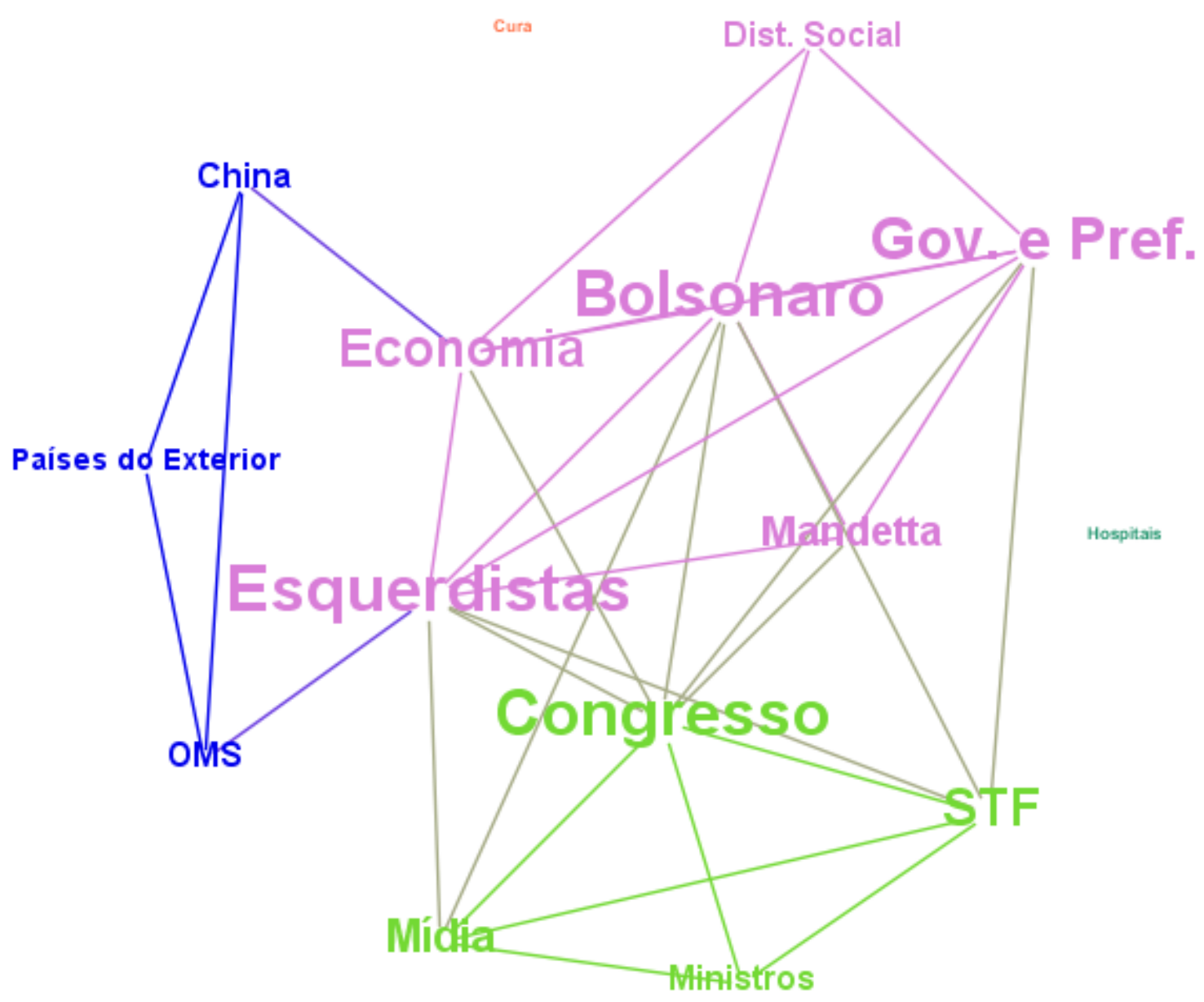

Fonte: Dados da pesquisa (2020).

Com base na frequência dos temas em combinação com a leitura qualitativa das mensagens, descobrimos que as mensagens desinformativas frequentemente justificavam que as medidas de combate ao Covid-19 seriam prejudiciais à economia, mencionavam que as ações dos governadores e prefeitos eram problemáticas e tinham interesses contrários a Bolsonaro, afirmava que a mídia, o Congresso, os "esquerdistas", o Supremo Tribunal Federal e mesmo Mandetta eram parte de planos para prejudicar Bolsonaro. Além disso, diversas mensagens também apontavam como a China estava envolvida na pandemia (inclusive acusando o país de intencionalmente criar o vírus) e como se beneficiava economicamente do espalhamento do Covid-19 para outros países.

A análise das conexões entre os tópicos também apoia a nossa interpretação de que a desinformação sobre o Covid-19 no WhatsApp foi influenciada pelo discurso político, tratando o tema não como algo de saúde pública, mas como um embate ideológico. "Esquerdistas", a forma como atores da oposição a Bolsonaro eram chamados em várias das mensagens, é o tópico mais central, aparecendo conectado a quase todos os atores políticos que discordaram do presidente nas formas de combate ao Covid-19. Também "Bolsonaro" é um tópico central, associado a autoridades de saúde e medidas como distanciamento social (as quais o político criticava). Vemos, portanto, que a desinformação sobre o Covid-19 enquadra a pandemia como um tema político e utiliza uma estratégia discursiva de opor "nós" (o lado 
"bom", que apoia a atuação de Bolsonaro) a "eles" (o lado "mau", que busca conspirar contra o presidente e contra o país). Este discurso favorece a polarização sobre o debate relacionado a pandemia (ALLCOTT et al., 2020).

O enquadramento da pandemia pelo discurso político também se reflete nas características da desinformação nos nossos dados. Na classificação dos tipos de desinformação, descobrimos que as teorias da conspiração eram o tipo de desinformação mais frequente no nosso conjunto de dados (324 mensagens - 41\%). As teorias da conspiração foram seguidas de perto pela distorção (315 - 39\%) e as informações fabricadas foram o tipo de desinformação menos frequente nos nossos dados (163 - 20\%).

Estes resultados são, de alguma forma, surpreendentes. Estudos que classificaram os tipos de desinformação sobre o Covid-19 em outras plataformas, identificaram a distorção como o tipo de desinformação mais comum. Mais da metade da desinformação produzida no Twitter, Facebook e YouTube, analisada por Brennen et al. (2020), foi considerada distorção, enquanto apenas $17 \%$ foi identificada como teoria da conspiração. No contexto brasileiro, mais $75 \%$ das mensagens desinformativas sobre a hidroxicloroquina no Twitter se enquadravam na categoria de distorção (RECUERO \& SOARES, 2020).

A proeminência de teorias da conspiração no WhatsApp pode estar relacionada com a característica mais privada na forma como os usuários percebem a plataforma (VALERIANI \& VACCARI, 2017). Em função da menor exposição do conteúdo que usuários compartilham, assim como maior controle em sua audiência, o WhatsApp parece favorecer o espalhamento de teorias da conspiração. Além disso, geralmente há maior alinhamento interno dos grupos na plataforma, o que pode resultar em menor questionamento sobre as conspirações. 0 nosso resultado é semelhante ao que foi observado na campanha de desinformação sobre as urnas eletrônicas em 2018, em que a quantidade de teorias da conspiração no WhatsApp foi superior a este tipo de desinformação no Twitter, que é uma plataforma "mais pública" (RECUERO, SOARES \& VINHAS, 2021). Isto reforça a hipótese de que as affordances das plataformas afetam diretamente as características da desinformação, ou seja, que as características do WhatsApp e as práticas sociais presentes em seus usos afetam o tipo de conteúdo que é produzido e circula na plataforma.

As teorias da conspiração também apresentam correlação positiva com a maioria dos tópicos das mensagens, especialmente temas políticos. Por exemplo, a mídia (Pearson's 0,2, $p<0,001)$, os "esquerdistas" e comunistas $(0,182, p<0,001)$, o congresso $(0,148, p<0,001)$ e o $\operatorname{STF}(0,079, p<0,05)$ aparecem envolvidos em várias narrativas que afirma que estes atores estavam conspirando contra Bolsonaro $(0,07, p<0,05)$ durante a pandemia do Covid-19, como no exemplo abaixo (Figura 5). 
Figura 5 - Exemplo de teoria da conspiração

OS BANDIDOS VERMINOSOS PILANTRAS COMUNISTAS MAIA, ALCOLUMBRE+TOFOLLI E DÓRIA ESTÃO COORDENANDO UM PLANO MACABRO PARA DEPOR NOSSO PRESIDENTE HOJE!!! ESTÃO SE APROVEITANDO DA CRISE DO CORONAVÍRUS, MANIPULADA PELA MÍDIA COMUNISTA, GLOBOLIXO+CNN+BAND PARA CAUSAR O CAOS SOCIALE, ASSIM, CULPAR O PRESIDENTE. O PRESIDENTE BOLSONARO PRECISA ACIONAR O "ESTADO DE DEFESA", IMEDIATAMENTE, PARA SALVAR A NAÇÃO DA DESGRAÇA DO CAOS ECONÔMICO!! QUEREM NOS TRANSFORMAR EM UMA NOVA E 1.000 .000 DE VEZES PIOR VENEZUELA! A DECRETAÇÃO DO "ESTADO DE DEFESA" NÃO DEPENDE DA APROVAÇÃO DO MALDITO CONGRESSO+ STF. É PRERROGATIVA EXCLUSIVA DO PODER EXECUTIVO!!

Fonte: Dados da pesquisa (2020).

China $(0,534, p<0,001)$ também apareceu com correlação positiva com teorias da conspiração, sendo a correlação mais forte entre um tema e um tipo de desinformação no contexto dos nossos dados. Estas mensagens também reproduziam um discurso de cunho político e buscavam acusar a China (representante do Comunismo) de intencionalmente criar o vírus para obter ganhos econômicos, como no exemplo abaixo (Figura 6).

Figura 6 - Exemplo de teoria da conspiração

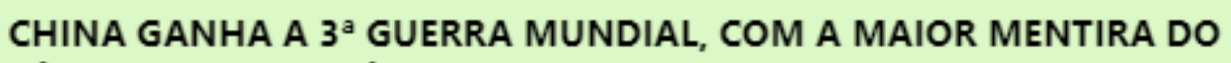
SÉCULO: "CORONAVÍRUS!" A China covardemente acaba de ganhar a $3^{\mathrm{a}}$ Guerra mundial com mentiras biológicas, um golpe econômico e mentiroso, destruiu todas as economias produtivas que negociavam com ela sem disparar um único tiro. A China é covarde, cruel e mentirosa, essa é a China comunista, nua e crua. Passaremos meses tentando recuperar o estrago causado por esse monstro, chamado China!!! Com a crise causada por eles, compraram bilhões em empresas mundiais, e podem estar muito perto do seu controle agora, viraremos escravos, assim como seu povo, garantindo os privilégios de uma elite comunista e voraz! Depois do anúncio e das quedas violentas das bolsas no mundo inteiro, a China imediatamente, compra com uma gigantesca desvalorização, a maioria das ações das empresas estrangeiras, que estão aonde? Na China é claro, que grande coincidência!!! Porque? Porque agora a China passa a ser a maior acionista de todas, eu falei de "todas" as empresas estrangeiras instaladas, aonde mesmo? Na china, olha só outra grande coincidência!!! A China já começa desmontar os hospitais montados, para o controle do vírus, e diz para o mundo: Muito obrigado otários, já podem voltar as suas vidinhas normais, já ganhamos muito dinheiro e poder, a China COMUNISTA agradece."

Fonte: Dados da pesquisa (2020).

Mensagens contendo distorção e informações fabricadas também foram utilizadas para reforçar esta narrativa política da pandemia. As mensagens com distorção possuem correlação positiva com o tópico distanciamento social $(0,285, p<0,001)$. Também nestes casos, vemos uma conexão com o discurso político, já que estas mensagens ecoam as mani- 
festações de Bolsonaro contrárias a medidas adotadas por governadores e prefeitos (Figura 7). Já as mensagens com informações fabricadas possuem correlação positiva com cura $(0,085, p<0,05)$ e mencionavam, por exemplo, o uso da hidroxicloroquina para o combate do Covid-19 (Figura 8). Estudos científicos já comprovaram que o medicamento é ineficaz no tratamento da doença, mas Bolsonaro inúmeras vezes mencionou a hidroxicloroquina como "cura" para o vírus.

Figura 7 - Exemplo de distorção

RESUMO DO DISCURSO do Bolsonaro. 1. Pessoas que não são grupos de risco devem voltar ao trabalho para o país não falir. 2. Mas, quem é grupo de risco (pessoas acima de 60 anos, gestantes, com baixa imunidade, pressão alta, diabéticos, com câncer, etc), deve permanecer em isolamento. MÁ INTERPRETAÇÃO QUE EU NOTEI ENTRE AS PESSOAS: 1. Algumas pessoas acharam que ele disse pra todo mundo voltar, o que não é verdade. 2 . Algumas pessoas não entenderam a referência sobre a gripe, pois não acompanham o Twitter, nem a pessoa que Bolsonaro citou que falou a mesma coisa, que no caso é o Drauzio Varella. Enfim, é algo que não acrescenta nada ao discurso. OU SEJA - saudáveis trabalhando. - grupos de risco isolados. POR QUÊ? - senão o país vai quebrar. - alguns governadores já estão fechando suas cidades e não estão nem deixando entrar comida. - alguns outros governadores mandaram saquear distribuidoras de remédios. - o caos vai se instalar com o pânico e histeria. Faça a sua parte, mantenha os amigos bem informados

Fonte: Dados da pesquisa (2020).

Figura 8 - Exemplo de informação fabricada

Diabética de 97 anos com apenas um rim, histórico de câncer e doenças cardíacas é curada com hidroxicloroquina e azitromicina - [URL de site hiperpartidário]

Fonte: Dados da pesquisa (2020).

Entre as estratégias discursivas, a mais frequente nos nossos dados foi o uso de opinião, que apareceu em aproximadamente três quartos das mensagens. Já as menções a autoridades e o uso de call to action apareceram, respectivamente, em aproximadamente um quinto e quarto das mensagens. A tabela 1 detalha como estas estratégias apareceram nas mensagens que analisamos.

Tabela 1 - Relação entre estratégias discursivas e tipo de desinformação

\begin{tabular}{|c|c|c|c|c|c|}
\hline \multicolumn{2}{|c|}{} & Distorção & Fabricada & Conspiração & Total \\
\hline \multirow{2}{*}{ Opinião } & Mensagens & $240(76,2 \%)$ & $91(55,8 \%)$ & $282(87 \%)$ & \multirow{2}{*}{$613(76,4 \%)$} \\
\cline { 2 - 5 } & Pearson's & 0,027 & $-0,188^{* *}$ & $0,169 * *$ & \\
\hline \multirow{2}{*}{ Autoridade } & Mensagens & $48(15,2 \%)$ & $76(46,6 \%)$ & $40(12,3 \%)$ & \multirow{2}{*}{$163(20,3 \%)$} \\
\cline { 2 - 5 } & Pearson's & $-0,129 * *$ & $0,301 * *$ & $-0,109 *$ & \\
\hline \multirow{2}{*}{$\begin{array}{c}\text { Call to ac- } \\
\text { tion }\end{array}$} & Mensagens & $63(20 \%)$ & $44(27 \%)$ & $82(25,3 \%)$ & \multirow{2}{*}{$189(23,6 \%)$} \\
\cline { 2 - 5 } & Pearson's & 0,023 & $-0,005$ & $-0,036$ & \\
\hline \multicolumn{5}{r}{$p<0,005, * * p<0,001$} \\
Fonte: Dados da pesquisa (2020).
\end{tabular}


Como podemos observar nos dados acima, opinião tem correlação positiva com teorias da conspiração, o que mostra que o uso de opinião foi uma estratégia discursiva comum neste tipo de desinformação. A opinião é usada nas teorias da conspiração para justificar as conexões entre eventos específicos que geram as narrativas conspiratórias, como no exemplo: "*SOBRE O CORONAVÍRUS, DÓLAR E GOVERNO OCULTO* Bom dia a todos, aqui é o Gevaerd. Tirei o final tarde e começo da noite de ontem para ler na imprensa nacional e internacional sobre as ameaças do coronavírus. [...]". Este tipo de estratégia também parece estar associada com o tipo de interação do WhatsApp, que é mais informal e entre indivíduos com laços mais próximos (VALERIANI \& VACCARI, 2017). Ainda que os testes de correlação apontem para uma predominância da opinião como estratégia discursiva em mensagens com teorias da conspiração, a opinião tem grande prevalência nos dados e também está presente na maioria das mensagens com distorções ou informações fabricadas. No uso da opinião em mensagens com distorção, a estratégia discursiva é utilizada justamente para "interpretar" algum acontecimento político, gerando a distorção. Já no caso de informações fabricadas, a opinião é menos frequente que nos outros tipos de desinformação e é muitas vezes apresentada como opinião de terceiros (dando sentido de autoridade).

A autoridade como estratégia discursiva tem correlação positiva com informações fabricadas, enquanto possui correlação negativa com os outros dois tipos de desinformação. A autoridade é utilizada principalmente para legitimar as mensagens em função da credibilidade (VAN LEEWEN, 2007) de terceiros, como profissionais da saúde e instituições reconhecidas. A Fiocruz, por exemplo, é utilizada para justificar uma informação fabricada sobre prevenção: "FIOCRUZ, UTILIDADE PÚBLICA SOBRE O CORONA VIRUS. [...] Gargarejar com água morna ou salgada mata os vírus que se alojem nas amígdalas e evita que passem para os pulmões. Estas medidas são suficientes para evitar a ocorrência e propagação do vírus em qualquer parte do mundo.". Em outro exemplo, um áudio fabricado de um médico é utilizado para defender Bolsonaro: "Visão de um médico brasileiro e residente no Canadá sobre a atuação do Governo Brasileiro comandado por Jair Bolsonaro [...]". Enquanto esta estratégia aparece em quase metade das mensagens com informações fabricadas, o uso da autoridade é menos comum nos outros tipos de desinformação. Isto indica que a autorização por meio do argumento da autoridade (VAN LEEUWEN, 2007) é utilizado como uma estratégia de legitimação de informações fabricadas.

Call to action não teve correlações positivas ou negativas com nenhum tipo de desinformação. Esta estratégia foi utilizada em aproximadamente um quarto das mensagens e sua principal função foi motivar usuários a compartilhar o conteúdo, com expressões, frequentemente em caixa alta ou com destaque a urgência, como "DIVULGUE NOS GRUPOS E REDES SOCIAIS", "COMPARTILHEM COM SEUS GRUPOS DE WHATSAPP" e "Façam isso chegar ao número máximo de pessoas pelo amor de Deus!". Esta estratégia é importante no WhatsApp, porque o espalhamento das mensagens depende do repasse de usuários para outros contatos e grupos, questão também relacionada com as affordances da plataforma, já que a circulação de informações no WhatsApp é bastante dependente da ação de repasse dos usuários. Assim, nestes casos, o call to action foi principalmente utilizado para gerar um sentimento de urgência e motivar usuários a compartilhar o conteúdo. O call to action também apareceu no contexto de manifestações pró-Bolsonaro, em que a estratégia era utilizada para convocar usuários para participar das manifestações, como neste exemplo: "[...] Assim, convocamos a todos para que venham conosco em Copacabana [...] expressarmos nosso apoio ao Governo [...] IREMOS AS RUAS SIM ! [...] NÃO DEIXEM DE IR DOMINGO DIA 15 DE MARÇO NAS MANIFESTAÇÕES POPULARES PATRIÓTICAS". Nestes casos, a estratégia serve 
para reforçar o enquadramento político da desinformação sobre o Covid-19, buscando gerar apoio a Bolsonaro, que sofria com crises em seu governo.

Assim, vemos que as estratégias discursivas servem também para fortalecer o discurso político da desinformação, que enquadrou a pandemia do Covid-19 não como um problema de saúde pública, mas como um embate ideológico. Dentre as principais consequências deste enquadramento ideológico, que foi visto nos exemplos dos tipos de desinformação, nos temas mais frequentes e também nas estratégias discursivas, é uma pior resposta coletiva no combate ao vírus. Isto gera também uma polarização nos sentimentos relacionados a pandemia, de forma que as visões sobre as melhores formas de prevenção e combate ao vírus tendem a se polarizar (ALLCOTT et al., 2020).

O enquadramento da pandemia como tema político na desinformação também parece servir como resposta à crise política pela qual passava o governo Bolsonaro. Como identificamos na nossa análise, as temáticas centrais são questões políticas e refletem principalmente os posicionamentos de Bolsonaro expressos em seus pronunciamentos nos dias 24 e 31 de março e também em outras situações. Além disso, percebemos como os dois pronunciamentos tem impacto no aumento da circulação de desinformação. Assim, a desinformação parece ser utilizada como uma resposta ao momento político, para combater a crise, para "apagar um incêndio" (PAUL \& MATTHEWS, 2016) do governo Bolsonaro. Desta forma, o espalhamento de desinformação no WhatsApp favorece uma "narrativa alternativa" àquela apresentada pela imprensa, baseada em hiperpartidarismo (STARBIRD, 2017; BENKLER, FARIS \& ROBERTS, 2018). Entendemos, portanto, que é importante analisar a desinformação em relação ao contexto político e social em que aparece, afinal, é nesta relação que aparecem pistas sobre as motivações e estratégias para a propagação da desinformação.

Vimos também como as affordances do WhatsApp favorecem certos tipos de desinformação e motivam o uso de estratégias discursivas específicas. Ainda que outros estudos tenham identificado teorias da conspiração relacionadas ao Covid-19, elas tendem a ser menos frequentes que outros tipos de desinformação, como a distorção (BRENNEN et al., 2020; GRUZD \& MAI, 2020; PAPAKYRIAKOPOULOS, SERRANO \& HEGELICH, 2020; RECUERO \& SOARES, 2020). Nos nossos dados, porém, as teorias da conspiração são maioria e aparecem frequentemente associadas ao uso de opinião. O WhatsApp permite mensagens mais longas que o Twitter, por exemplo, o que facilita a construção de uma narrativa conspiratória (RECUERO, SOARES \& VINHAS, 2021). Além disso, vemos que a forma como os usuários percebem a plataforma, como um espaço mais privado (VALERIANI \& VACCARI, 2017), parece também influenciar essa combinação de estratégias, já que o espalhamento de conspirações apresentadas como opiniões tende a ser facilitado em espaços mais privados e interações com laços mais fortes.

Também identificamos que estratégias como call to action são utilizadas para fazer as mensagens circular. Como o conteúdo só se propaga no WhatsApp por meio do repasse de usuários indivíduas, esta estratégia é importante para aumentar a visibilidade da desinformação. Além disso, ao repassar, os usuários de alguma forma legitimam aquele conteúdo, que agora está associado a forma como seus contatos o percebem. Assim, o call to action é utilizado para motivar usuários a repassar, por meio de um sentimento de urgência, o que favorece o espalhamento da desinformação. Neste sentido, o call to action opera uma prática de consumo e distribuição de informações aligeirada, que pode reduzir a verificação das informações em função da urgência no repasse.

Mesmo informações fabricadas, que frequentemente utilizaram da autoridade como estratégia discursiva, aparecem associadas ao espaço específico do WhatsApp. Frequente- 
mente, as informações fabricadas eram repassadas em formato de áudio, mídia típica do WhatsApp, em que autoridades eram utilizadas para dar credibilidade ao conteúdo. Em alguns casos, a fabricação estava na autoridade em si (que eram inventadas: "o médico Fulano de Tal") ou no conteúdo, em que a autoridade era utilizada para legitimar. Entendemos, portanto, que levar em conta as affordances e as práticas sociais das plataformas é fundamental para compreender as estratégias de espalhamento de desinformação nestes espaços.

\section{CONSIDERAÇÕES FINAIS}

Neste artigo, analisamos os enquadramentos e estratégias na propagação de desinformação sobre o Covid-19 no WhatsApp no contexto brasileiro. Com os objetivos de (1) analisar a influência do discurso político na desinformação sobre a pandemia e (2) caracterizar a desinformação sobre o Covid-19 no WhatsApp, analisamos um conjunto de 802 mensagens que circularam nos meses de março e abril nos grupos monitorados pelo Monitor do WhatsApp (RESENDE et al., 2018). Utilizamos a análise de conteúdo para categorizar estas mensagens, além de testes estatísticos e análise de redes para explorar alguns dos nossos resultados.

Dentre os nossos principais resultados, percebemos que (1) a pandemia foi enquadrada como tema político para favorecer uma narrativa pró-Bolsonaro e combater a crise política sofrida pelo governo. Isto foi identificado, por exemplo, nos temas presentes nas mensagens, que frequentemente apontavam as medidas de combate a pandemia como formas de prejudicar Bolsonaro. Além disso, teorias da conspiração acusavam a oposição do governo de se apropriar da pandemia como forma de prejudicar Bolsonaro.

Também identificamos que (2) as teorias da conspiração, frequentemente ancoradas em opiniões, foram o tipo de desinformação mais comum. Entendemos que isto se dá pelo caráter mais privado do WhatsApp, em que usuários interagem com contatos com os quais compartilham laços mais fortes, em relação com as affordances da plataforma, que geram práticas sociais distintas de outros espaços como Twitter e Facebook, por exemplo. Além disso, identificamos que estratégias como o call to action são utilizadas para motivar os usuários a repassar o conteúdo desinformativo.

Este estudo tem algumas limitações. O Monitor das Eleições coleta apenas dados de grupos públicos. Ainda que o número de grupos monitorados seja expressivo, reconhecemos que é possível que interações interpessoais em outros contextos do WhatsApp se apoiem em outras formas de desinformação. Assim, temos um retrato do que é distribuído principalmente em grandes grupos, utilizados para "troca de informações" (RESENDE et al., 2018). Além disso, analisamos apenas dados textuais e a desinformação também circula de outras formas. Ainda que a nossa análise compreenda vídeos, áudios e imagens que circulam de forma conjunta com texto, não analisamos mensagens multimídia que não são acompanhadas por texto. Há, ainda, um viés nos grupos monitorados, já que vários deles possuem posicionamento de apoio a Bolsonaro, de forma que isso pode ter influenciado o alto número de desinformação pró-Bolsonaro que encontramos.

\section{REFERÊNCIAS}

ALBUQUERQUE, A.; QUINAN, R. Crise epistemológica e teorias da conspiração: o discurso anti-ciência do canal "professor terra plana". Revista Mídia e Cotidiano, v. 13, n. 3, p. 83104, 2019. DOI: https://doi.org/10.22409/rmc.v13i3.38088. 
ALLCOTT, H.; BOXELL, L.; CONWAY, J. C.; GENTZKOW, M.; THALER, M.; YANG, D. Y. Polarization and Public Health: Partisan Differences in Social Distancing during the Coronavirus Pandemic (Working Paper No. 26946; Working Paper Series). National Bureau of Economic Research. 2020. DOI: https://doi.org/10.3386/w26946.

ARAÚJO, R.; OLIVEIRA, T. A. Desinformação e mensagens sobre a hidroxicloroquina no Twitter: da pressão política à disputa científica. Atoz: novas práticas em informação e conhecimento, v. 9, n. 2, p. 196-205, 2020. DOI: http://dx.doi.org/10.5380/atoz.v9i2.75929.

BAPTISTA, E. A.; ROSSINI, P.; OLIVEIRA, V. V., STROMER-GALLEY, J. A circulação da (des)informação política no WhatsApp e no Facebook. Lumina, v. 13, n. 3, p. 29-46, 2019.

BENKLER, Y.; FARIS, R.; ROBERTS, H. Network Propaganda: Manipulation, disinformation, and radicalization in American politics. New York: Oxford University Press, 2018.

BLONDEL, V, D.; GUILLAUME, J,; LAMBIOTTE, R,; LEFEBVRE, E. Fast unfolding of communities in large networks. [physics.soc-ph], 2008. Disponível em: http://lanl.arxiv.org/abs/0803.0476.

BRENNEN, S.; SIMON, F.; HOWARD, P. N.; NIELSEN, R. K. Types, sources, and claims of COVID-19 misinformation. Oxford: Reuters Institute Factsheet, 2020. Disponível em: $<$ https://reutersinstitute.politics.ox.ac.uk/types-sources-and-claims-covid-19misinformation>.

D'ANDRÉA, C. Pesquisando plataformas online: conceitos e método. Salvador: EDUFBA, 2020.

EVANS, S. K.; PEARCE, K. E.; VITAK, J.; TREEM, J. W. Explicating Affordances: a Conceptual Framework for Understanding Affordances in Communication Research. Journal of Computer-Mediated Communication, v. 22, n. 1, p. 35-52, 2017. DOI: https://doi.org/10.1111/jcc4.12180.

FAIRCLOUGH, N. Discurso e mudança social. Brasília: Editora UnB, 2001.

FALLIS, D. What Is Disinformation?. Library Trends, v. 63, n. 3, p. 401-426, 2015.

FREELON, D. ReCal: Intercoder reliability calculation as a web service. International Journal of Internet Science, v. 5, n. 1, p. 20-33, 2010.

GRUZD, A.; MAI, P. Going viral: How a single tweet spawned a COVID-19 conspiracy theory on Twitter. Big Data \& Society, v. 7, n. 2, p. 1-9, 2020.

GUESS, A. M.; LYONS, B. A. Misinformation, Disinformation, and Online Propaganda. In: PERSILY, N.; TUCKER, J. A. (Org.). Social Media and Democracy: The State of the Field and Prospects for Reform. Cambridge: Cambridge University Press, 2020. 
HARAMBAM, J.; AUPERS, S. Contesting epistemic authority: Conspiracy theories on the boundaries of science. Public Understanding of Science, v. 24, n. 4, p. 466-480, 2015. DOI: 10.1177/0963662514559891.

KRIPPENDORFF, K. Content Analysis: An Introduction to Its Methodology. California, CA: Sage Publications, 2013.

NEWMAN, N.; FLETCHER, R.; SCHULZ, A.; ANDI, S.; NIELSEN, R. K. Reuters Institute Digital News Report 2020. Oxford: Reuters Institute, Oxford University, 2020.

OLIVEIRA, T. M. Como enfrentar a desinformação científica? Desafios sociais, políticos e jurídicos intensificados no contexto da pandemia. Liinc Em Revista, v. 16, n. 2, 2020a. DOI: https://doi.org/10.18617/liinc.v16i2.5374.

OLIVEIRA, T. Desinformação científica em tempos de crise epistêmica: circulação de teorias da conspiração nas plataformas de mídias sociais. Fronteiras - estudos midiáticos, v. 22, n. 1, p. 21-35, 2020b. DOI: 10.4013/fem.2020.221.03.

PAPAKYRIAKOPOULOS, O.; SERRANO, J. C. M.; HEGELICH, S. The spread of COVID-19 conspiracy theories on social media and the effect of content moderation. The Harvard Kennedy School (HKS) Misinformation Review, 2020. DOI: https://doi.org/10.37016/mr-2020-034.

PAUL, C., MATTHEWS, M. The Russian "Firehose of Falsehood" Propaganda Model: Why It Might Work and Options to Counter It. RAND Corporation, Santa Monica, CA, 2016. Disponível em https://www.rand.org/pubs/perspectives/PE198.html

RECUERO, R. \#FraudenasUrnas: estratégias discursivas de desinformação no Twitter nas eleições 2018. Rev. bras. linguist. apl., v. 20, n. 3, 2020. DOI: https://doi.org/10.1590/19846398202014635.

RECUERO, R.; SOARES, F. O Discurso Desinformativo sobre a Cura do COVID-19 no Twitter: Estudo de caso. E-Compós, Ahead of Print, 2020. DOI: https://doi.org/10.30962/ec.2127.

RECUERO, R.; SOARES, F.; VINHAS, O. Discursive Strategies for Disinformation on WhatsApp and Twitter during the 2018 Brazilian Presidential Election. First Monday, v. 26, n. 1. DOI: https://doi.org/10.5210/fm.v26i1.10551.

RECUERO, R.; SOARES, F. B.; ZAGO, G. Polarization, Hyperpartisanship and Echo Chambers: How the disinformation about Covid-19 circulates on Twitter. Contracampo, Ahead of Print, 2021: https://periodicos.uff.br/contracampo/article/view/45611.

REIS, J. C. S.; MELO, P.; GARIMELLA, K.; BENEVENUTO, F. Can WhatsApp benefit from debunked fact-checked stories to reduce misinformation?. The Harvard Kennedy School (HKS) Misinformation Review, v. 1, n. 5, 2020. DOI: https://doi.org/10.37016/mr-2020-035.

RESENDE, G.; MESSIAS, J.; SILVA, M.; ALMEIDA, J.; VASCONCELOS, M.; BENEVENUTO, F. A System for Monitoring Public Political Groups in WhatsApp. Proceedings of the 24th Brazili- 
an Symposium on Multimedia and the Web (WebMedia '18). Association for Computing Machinery, New York, NY, USA, 387-390, 2018. DOI:

https://doi.org/10.1145/3243082.3264662.

RICARD, J.; MEDEIROS, J. Using Misinformation as a political weapon: COVID-19 and Bolsonaro in Brazil. The Harvard Kennedy School (HKS) Misinformation Review. 2020. DOI: https://doi.org/10.37016/mr-2020-013.

SOARES, F. B. Esfera pública e desinformação: estratégias de circulação e legitimação da desinformação. In: Encontro Anual da Compós, XXVIII, Pontifícia Universidade Católica do Rio Grande do Sul, Porto Alegre. Anais... São Paulo: Compós, 2018. Disponível em http://www.compos.org.br/biblioteca/trabalhos_arquivo_7E57XD7TP72900YNLQX9_28_75 48_18_02_2019_10_15_21.pdf.

STARBIRD, K. Examining the Alternative Media Ecosystem through the Production of Alternative Narratives of Mass Shooting Events on Twitter. Proceedings of the Eleventh International AAAI Conference on Web and Social Media (ICWSM 2017), Montreal, Canadá, AAAI, p. 230-239, 2017. Disponível em:

https://aaai.org/ocs/index.php/ICWSM/ICWSM17/paper/view/15603.

SUNSTEIN, C. R.; VERMEULE, A. Conspiracy Theories: Causes and Cures. The Journal of Political Philosophy, v. 17, n. 2, p. 202-227, 2009. DOI: https://doi.org/10.1111/j.1467-

9760.2008.00325.x.

TSFATI, Y.; BOOMGAARDEN, H. G.; STRÖMBÄCK, J.; VLIEGENTHART, R.; DAMSTRA, A.; LINDGREN, E. Causes and consequences of mainstream media dissemination of fake news: literature review and synthesis. Annals of the International Communication Association, v. 44, n. 2, p. 157-173, 2020. DOlhttps://doi.org/10.1080/23808985.2020.1759443.

TUCKER, J. A.; GUESS, A.; BARBERA, P.; VACCARI, C.; SIEGEL, A.; SANOVICH, S.; STUKAL, D.; NYHAN, B. Social Media, Political Polarization, and Political Disinformation: A Review of the Scientific Literature. Menlo Park, CA: Hewlett Foundation, 2018. DOI: http://dx.doi.org/10.2139/ssrn.3144139.

VALERIANI, A.; VACCARI, C. Political talk on mobile instant messaging services: a comparative analysis of Germany, Italy, and the UK. Information, Communication \& Society, v. 21, n. 11, p. 1715-1731, 2018. DOI: 10.1080/1369118X.2017.1350730.

VAN LEEWEN, T. Legitimation in discourse and communication. Discourse and Communication, v. 1, n. 1, p. 91-112, 2007. DOI: 10.1177/1750481307071986.

WARDLE, C. Understanding Information Disorder. Brighton: First Draft, 2019.

WARDLE, C.; DERAKHSHAN, H. Information disorder: Toward an interdisciplinary framework for research and policy making. Strasbourg: Council of Europe, 2017. 
WODAK, R. The discourse historical approach. In: WODAK, R.; MEYER, M. (Org.). Methods of critical discourse analysis. London, England: SAGE, 2001 (p. 64-94). 